\title{
MOF Derived Catalysts for Oxygen Reduction Reaction in Proton Exchange Membrane Fuel Cell
}

\author{
NOAMAN Khan ${ }^{1, a^{*}}$, SAIM Saher ${ }^{3, b}$, XUAN Shi ${ }^{2, c}$, MUHAMMAD Noman $^{1, d}$, \\ MUJAHID Wasim Durani ${ }^{2, e}$, ASAD Ali ${ }^{1, f}$
}

\begin{abstract}
${ }^{1}$ Materials for Energy Storage and Conversion, U.S.-Pakistan Center for Advanced Studies in Energy (USPCAS-E), University of Engineering and Technology (UET) Peshawar, 25000, Khyber Pakhtunkhwa, Pakistan
\end{abstract}

${ }^{2}$ Fuel Cell Laboratory, The Polytechnic School, Ira A. Fulton Schools of Engineering, Arizona State University, Mesa, AZ 85212, USA

${ }^{3}$ Department of Mechanical Engineering, CECOS University of Information Technology and Emerging Sciences, Peshawar, Khyber Pakhtunkhwa, Pakistan

ankhan29@asu.edu, bs.saher@uetpeshawar.edu.pk, 'Shi.Xuan@asu.edu, dmuhammad.noman@uetpeshawar.edu.pk, ${ }^{\mathrm{e}}$ mdurani@asu.edu, ${ }^{\mathrm{f}}$ asadali3201@gmail.com

Keywords: Zeolitic Imidazole Frameworks, Metal Organic Frameworks, Nitrogen-Doped Carbon Nanotubes, Oxidation Reduction Reaction, Electrocatalysts, PEMFC

\begin{abstract}
Highly porous ZIF-67 (Zeolitic imidazole framework) has a conductive crystalline metal organic framework (MOF) structure which was served as a precursor and template for the preparation of nitrogen-doped carbon nanotubes (NCNTs) electrocatalysts. As a first step, the chloroplatinic acid, a platinum $(\mathrm{Pt})$ precursor was infiltrated in ZIF-67 with a precise amount to obtain $0.12 \mathrm{mg} . \mathrm{cm}^{-2} \mathrm{Pt}$ loading. Later, the infiltrated structure was calcined at $700{ }^{\circ} \mathrm{C}$ in $\mathrm{Ar}: \mathrm{H}_{2}$ (90:10 vol\%) gas mixture. Multi-walled nitrogen-doped carbon nanotubes were grown on the surface of ZIF-67 crystals following thermal activation at $700{ }^{0} \mathrm{C}$. The resulting PtCo-NCNTs electrocatalysts were deposited on Nafion-212 solid electrolyte membrane by spray technique to study the oxygen reduction reaction (ORR) in the presence of $\mathrm{H}_{2} / \mathrm{O}_{2}$ gases in a temperature range of $50-70^{\circ} \mathrm{C}$. The present study elucidates the performance of nitrogen-doped carbon nanotubes ORR electrocatalysts derived from ZIF-67 and the effects of membrane electrode assembly (MEA) steaming on the performance of proton exchange membrane fuel cell (PEMFC) employing PtCoNCNTs as ORR electrocatalysts. We observed that the peak power density at $70{ }^{0} \mathrm{C}$ was $450 \mathrm{~mW} / \mathrm{cm}^{2}$ for steamed membrane electrode assembly (MEA) compared to $392 \mathrm{~mW} / \mathrm{cm}^{2}$ for an identical MEA without steaming.
\end{abstract}

\section{Introduction}

Proton exchange membrane fuel cell (PEMFC) is an interesting alternative energy source for future generations due to its high efficiency and environment-friendly operation. It converts chemical energy stored in hydrogen and oxygen to electricity, producing water as a byproduct. In recent times, conventional power sources such as fossil fuels have raised serious concerns due to rapid depletion, global warming and climate change. PEMFC has many advantages such as high power density, compact size, and low operating temperature in addition to its environment-friendly power generation $[1,2]$. However, the large scale commercialization is primarily hindered by the high cost of platinum based electrolcatalysts [1-4]. Platinum is an expensive and rare noble metal with 90\% supply from South Africa and Russia. Platinum must be significantly reduced or replaced altogether with low cost alternatives to promote PEMFC commercialization. In PEMFC, two reactions occur simultaneously at the cell anode and cathode called hydrogen oxidation reaction (HOR) and oxygen reduction reaction (ORR), respectively and are facilitated by platinum based electrocatalysts. ORR is inherently sluggish due to slow kinetics, requiring a high platinum loading at the cathode $[5,6]$. Commercial catalysts employ platinum particles supported on high surface area inert carbon black support such as Vulcan XC-72. Despite many advantages, $\mathrm{Pt} / \mathrm{C}$ suffers long 
term durability issues resulting from the weak interaction between Pt and carbon black support. The Pt particles erodes in PEMFC acidic environment and agglomerates, which decreases the active surface area and hence performance [7-9]. A great deal of work has been dedicated to reduce platinum loading by improving Pt utilization and catalytic activity [10-12]. The performance and utilization of Pt nanoparticles strongly depends upon the structural and electronic properties of catalyst support material. Novel catalyst support materials with desirable properties can significantly reduce Pt loading without suffering performance. Nitrogen-doped carbon nanotubes (NCNTs) have been utilized as Pt catalyst supports and demonstrated a higher catalytic activity than commercial $\mathrm{Pt} / \mathrm{C}$ owing to its superior electronic and structural properties $[13,14]$. Metal-free NCNTs are catalytically activity towards ORR attributed to pyrrolic and pyridinic configuration of nitrogen in graphitic CNT structure [15]. Nitrogen doping also induces defects into CNT structure which increase edge plane exposure and result in higher catalytic activity [16]. Higgins and coworkers showed that nitrogen-doped carbon nanotubes support for Pt catalysts synthesized from nitrogen-rich ethylenediamine (ED) precursor performs much better than pyridine (Py-CNTs) precursor with lesser nitrogen content [17]. Chen and coworkers compared un-doped CNTs with nitrogen-doped carbon nanotubes $(\mathrm{CNx})$ and found that the structure and surface property of $\mathrm{CNx}$ leads to a higher dispersion of Pt on CNx compared to CNTs [18]. Another method of reducing Pt loading is to alloy it with other metals such as $\mathrm{Co}, \mathrm{La}, \mathrm{Ni}$ and $\mathrm{Pd}$, to name a few [19-21]. Recently, metal organic frameworks (MOFs) have attracted attention as a precursor for synthesis of novel nano-carbon electrocatalysts for fuel cells due to advantages such as low cost, tunable pore sizes, high thermal stability and desirable electrochemical properties [22, 23]. MOF-derived nano-carbon composites are microporous and poor graphitic degree unfavorable for ion and electron conduction [24]. Zeolitic imidazole frameworks (ZIF) is a subclass of MOFs rich in carbon and nitrogen with imidazole structure and $\mathrm{Co} / \mathrm{Fe}$ metal centers [25]. Xia and coworkers used ZIF-67 to synthesize metal-free nitrogen-doped carbon nanotube frameworks electrocatalysts with higher catalytic activity resulting from robust structure of the NCNTFs [26]. ZIF-67 derived NCNTs have been reported for super-capacitor electrode materials but rarely for fuel cells [27]. In addition to electrocatalysts, membrane electrode assembly optimization directly affects fuel cell performance. MEA conditioning procedures have been reported in literature [28, 29]. Zhiani and coworkers have reported three different on-line activation processes on membrane electrode assembly to achieve high cell performance. They demonstrated that steaming of MEA before conditioning procedures enhances cell performance by decreasing Ohmic resistance and mass and charge transport limitations [29]. Qi and coworker reported that steaming or boiling the catalyst-coated membrane $(\mathrm{CCM})$ in water increases catalyst utilization and performance [30]. Here, we report highly active nitrogen-doped carbon nanotubes derived from ZIF-67 to be used as an active support for nanosized Pt particles alloyed with Cobalt $(\mathrm{Co})$ and use steaming as a pre-conditioning procedure for the MEA. Single fuel cell tests showed a very high performance improvement due to the robust structure of NCNTs enhancing Pt utilization, synergetic effect resulting from catalytically active NCNTs catalyst support and MEA optimization through steaming.

\section{Experimental}

Preparation of ZIF-67. $8.73 \mathrm{~g}$ of $\mathrm{Co}\left(\mathrm{NO}_{3}\right)_{2} \cdot 6 \mathrm{H}_{2} \mathrm{O}$ was added to a mixture of $100 \mathrm{ml}$ of ethanol and $100 \mathrm{ml}$ of methanol and stirred for few minutes. In another beaker, $9.85 \mathrm{~g}$ of 2-methylimidazole was added to a mixture of $100 \mathrm{ml}$ of ethanol and $100 \mathrm{ml}$ of methanol. The two solutions were mixed under continuous stirring and kept at room temperature for 24 hours in a closed container. ZIF-67 particles precipitated and were collected by centrifuging, washed in ethanol and methanol three times and fully dried at $80{ }^{\circ} \mathrm{C}$ to get powder ZIF-67.

Synthesis of PtCo-NCNTs. The NCNTs were prepared by thermal treatment of crystalline ZIF-67 particles reported in published literature [31]. First, ZIF-67 particles were soaked in Chloroplatinic acid $\left(\mathrm{H}_{2} \mathrm{PtCl}_{6} \cdot 6 \mathrm{H}_{2} \mathrm{O}\right)$ solution $(5 \mathrm{wt} . \%$ in DI water) and the resulting mixture was dried for 3 hours to ensure complete drying. The powder was collected and heated in a tube furnace for 1.25 hours at $350{ }^{\circ} \mathrm{C}$ then the temperature was increased to $700{ }^{\circ} \mathrm{C}$ at a constant rate of $2{ }^{\circ} \mathrm{C}$ per minute and 
calcined for 3 hours under $\mathrm{Ar}: \mathrm{H}_{2}$ (90:10 vol. \%) environment. After calcination, the resulting powder was cooled under natural conditions and treated with $0.5 \mathrm{M}$ sulfuric acid solution for 5 hours to remove excess Cobalt. The PtCo-NCNTs electrocatalyts obtained were thoroughly washed with DI water to remove any traces of impurities and vacuum dried at $70{ }^{\circ} \mathrm{C}$.

Material Characterization. The morphology of ZIF-67 and PtCo-NCNTs were studied using Field-Emission Scanning Electron Microscope (HITACHI S-4700 FESEM). Powder X-ray Diffraction (XRD) peaks were collected using SIEMENS D5000 X-ray Diffractometer $(\mathrm{Cu} \mathrm{k \alpha}$, $\lambda=0.156 \mathrm{~nm}, 40 \mathrm{kV}$ and $35 \mathrm{~mA}$ ). For elemental analysis, Energy-dispersive X-ray Spectroscopy (EDS) was employed.

Electrochemical Single Cell Measurements.

Catalyst-Coated Membranes. Membrane electrode assembly (MEA) was prepared by micro spray technique using PtCo-NCNTs as cathode and commercial $\mathrm{Pt} / \mathrm{C}$ as anode electrocatalysts. The cathode catalyst ink was prepared by dispersing PtCo-NCNTs in Nafion solution (5 wt. \%) and isopropyl alcohol (IPA). For anode electrocatalysts, catalyst ink with commercial Pt/C (Tanaka TKK, Japan) catalyst was prepared. The catalyst ink was sprayed on a Nafion-212 ion exchange membrane to fabricate catalyst-coated membranes (CCM) with an active area of $5 \mathrm{~cm}^{2}$. The catalyst loadings were calculated by weighing the nafion-212 membrane, before and after the each electrocatalyts were sprayed. The catalyst loadings at anode and cathode were $0.2 \mathrm{mg} / \mathrm{cm}^{2} \mathrm{Pt}$ and $0.12 \mathrm{mg} / \mathrm{cm}^{2} \mathrm{Pt}$, respectively.

Gas Diffusion Layer. The gas diffusion layer (GDL) was fabricated using Teflonized carbon paper (with an area of $10 \times 10 . \mathrm{cm}) .0 .5 \mathrm{~g}$ of carbon particles (70\% Pure black carbon and 30\% VGCF) were dispersed in a mixture of DI water and sodium dodecyl sulfate (SDS) and magnetic-stirred for 15 minutes followed by sonicating. To improve the integrity and dispersion of GDL, Teflon was added to the mixture and stirred continuously before coating the slurry on carbon paper. The carbon paste was coated on the carbon paper using Easycoater and allowed to dry overnight followed by heat treatment at $350{ }^{\circ} \mathrm{C}$ for $1 \mathrm{~h}$. After heat treatment, the GDL was placed in warm DI water and dried.

Membrane Electrode Assembly Fabrication and Performance Evaluation. The MEAs were fabricated by placing gas diffusion layers (GDLs) on each side of the CCM and assembled in PEMFC test cell. The cell was tightened by applying a constant torque on bolts oppositely placed to each other on the cell. Fuel cell tests were carried out in Greenlight test station (G50 Fuel Cell Test Station, Hydrogenics, Canada) at $50{ }^{0} \mathrm{C}, 60{ }^{0} \mathrm{C}$, and $70{ }^{0} \mathrm{C}$ with $\mathrm{H}_{2} / \mathrm{O}_{2}$ at normal pressures by galvanostatic polarization. The relative humidity was held constant at $100 \%$.

Pre-Conditioning and Conditioning of the MEA. The pre-conditioning was performed as reported in literature $[29,30]$. Catalyst-coated membrane was first placed in a pressure cooker with steam for 10 minutes to hydrate Nafion within the catalyst layer. After assembly, the cell was connected to a steam injector. The steam was injected for 2 hours to the anode and cathode sides at a constant flow rate of $300 \mathrm{ml} / \mathrm{min}$. Both steamed and un-steamed MEAs were conditioned at constant voltage of $0.6 \mathrm{~V}$ for 8 hours. The cell performance with both MEAs was evaluated in single cell tests in Greenlight test station at different temperatures $\left(50{ }^{\circ} \mathrm{C}, 60{ }^{0} \mathrm{C}, 70{ }^{0} \mathrm{C}\right.$. $)$

\section{Results and Discussion}

The surface morphology and physical dimensions were studied under field-emission scanning electron microscope (FESEM). The crystalline structure of ZIF-67 is shown in Fig. 1(a) showing different sizes with the largest ones close to $2 \mu \mathrm{m}$. Fig. 1(b) shows carbon nanotubes densely formed at the surface of ZIF-67 crystals following pyrolysis at $700{ }^{0} \mathrm{C}$. ZIF-67 leftovers from pyrolysis are visible within hair-like PtCo-NCNTs. The incorporation of Pt from chloroplatinic acid did not change the initial ZIF-67 structure. It can be seen that the surface morphology of NCNTs is rough and disordered, resulting from defects induced by the incorporation of nitrogen. The incorporation of nitrogen into CNT structure disrupted the ordered planar hexagonal structure of carbon atoms in CNTs and resulted in the rough surface of the NCNTs [32]. The presence of 
uniformly distributed nitrogen on the surface of NCNTs also facilitated dispersion of Pt by providing nucleation sites. The NCNTs were well intertwined to provide a continuous conducting network as catalyst support. NCNTs without Pt are widely reported in published literature synthesized by different techniques [33-36]. This method, however, used a simple and low cost method to obtain nitrogen-rich NCNTs with a high BET surface area of $500 \mathrm{~m}^{2} / \mathrm{g}$ and nitrogen doping close to $2.4 \%$. XRD peaks for PtCo-NCNTs are shown in Fig. 2. The XRD peak at $2 \Theta$ value of $\sim 26.4$ showed the presence of graphitic carbon, confirming the presence of the CNTs. The Pt/Co alloy formed is also evident from the peaks and expected to enhance the electrochemical properties towards ORR [37]. Using Scherer equation, the average crystallite size for Pt was calculated to be approximately $10 \mathrm{~nm}$.
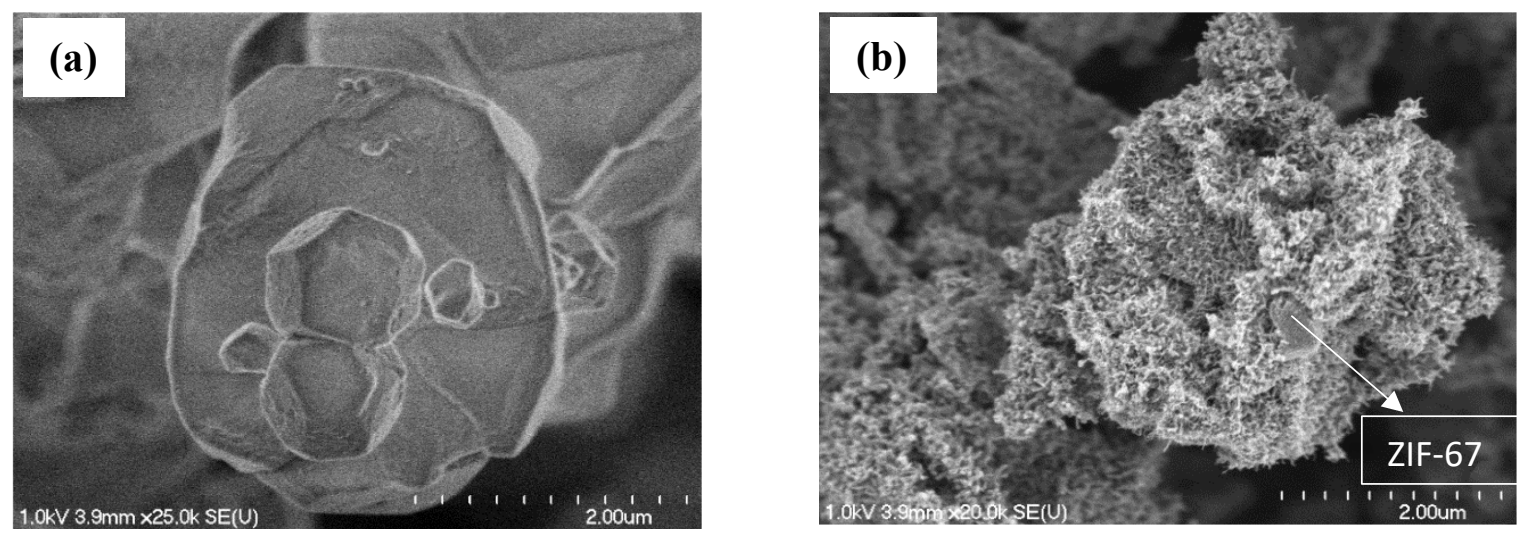

Fig. 1. SEM images of (a) ZIF-67 and (b) Nitrogen-doped carbon nanotubes (PtCo-NCNTs)

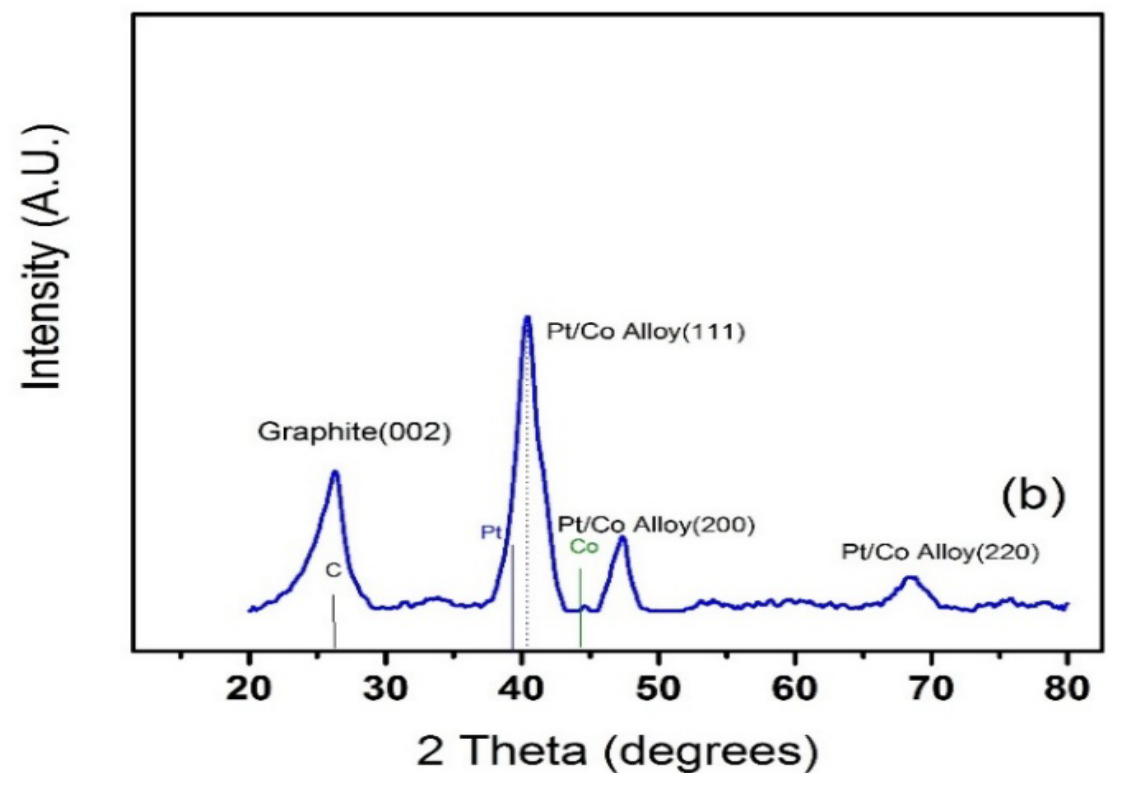

Fig. 2. XRD plot of PtCoNCNTs confirming the presence of $\mathrm{Pt} / \mathrm{Co}$ alloy and graphitic carbon NCNTs

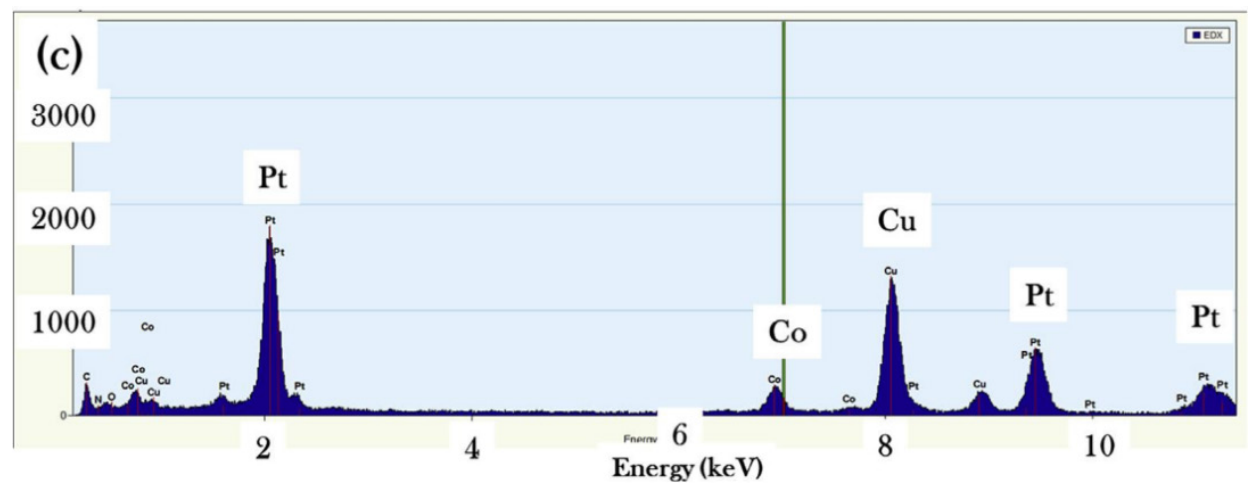

Fig. 3. EDS PtCo-NCNTs 
Fig. 3 shows EDS analysis for PtCo-NCNTs. The specific metals were identified in EDS and predominantly consisted of $\mathrm{Pt}$ but $\mathrm{Co}$ was also present in $\mathrm{Pt} / \mathrm{NCNTs}$. Fig. 4(a) shows the performance of the MEA with PtCo-NCNCTs as the cathode and commercial $\mathrm{Pt} / \mathrm{C}$ as anode electrocatalysts. Pt loadings at cathode and anode were $0.12 \mathrm{mg} / \mathrm{cm}^{2} \mathrm{Pt}$ and $0.2 \mathrm{mg} / \mathrm{cm}^{2} \mathrm{Pt}$, respectively. The $\mathrm{I} / \mathrm{C}$ (ionomer to catalyst ratio) was $0.85: 1$ in the catalyst-coated membrane. High peak power density of $392 \mathrm{~mW} / \mathrm{cm}^{2}$ was seen at $70{ }^{\circ} \mathrm{C}$ with $\mathrm{H}_{2}$ and $\mathrm{O}_{2}$ at $100 \% \mathrm{RH}$ at an ultra-low Pt loading. Fig. 4(b) shows the single cell performance of an identical MEA treated with steam. The loadings and testing conditions for the steamed MEA were identical to the previous one. Ionic conductor such as Nafion was added to the catalyst layer to make it active in three-dimensions. In order for Nafion to conduct protons $\left(\mathrm{H}^{+}\right)$efficiently, it must be sufficiently hydrated. The electrodes were dried completely before they were used in the cell, which reduced water content within catalyst-coated membranes. When the MEA was steam-treated, the Nafion was hydrated throughout the catalyst layer, increasing proton $\left(\mathrm{H}^{+}\right)$conductivity and hence the performance. The highest power density for MEA with steaming was close to $450 \mathrm{~mW} / \mathrm{cm}^{2}$ at $70{ }^{0} \mathrm{C}$. In general, the power density increases with temperature below the boiling point of water, which is critical to $\mathrm{H}^{+}$ conduction through Nafion electrolyte membrane. These results confirmed steaming as an efficient procedure for reducing MEA resistance and to improve power density without increasing the catalyst loading.
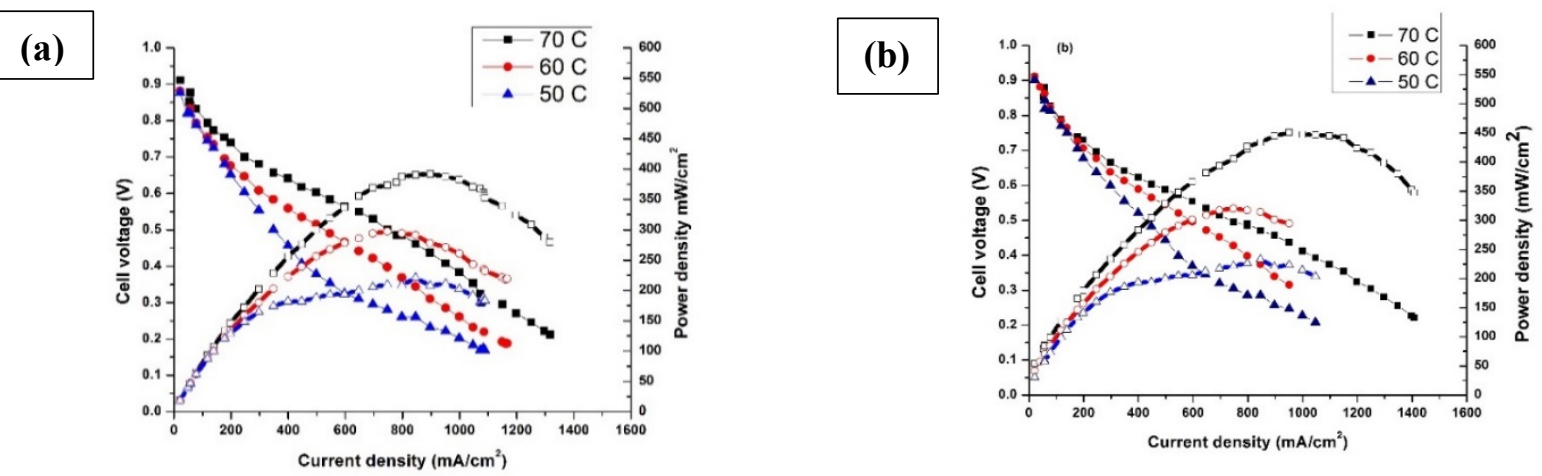

Fig. 4. Cell voltages and power densities as a function of current density measured in single fuel cell tests. (a) shows cell performance of MEA without steam treatment. (b) shows the current density vs power density for a steam-treated MEA under identical conditions and catalyst loadings

\section{Conclusions}

Highly active nitrogen-doped carbon nanotubes were synthesized from a low cost ZIF-67 precursor and used as a catalyst support for $\mathrm{Pt} / \mathrm{Co}$ alloy in proton exchange membrane fuel cell. Only ZIF-67 was the source of C, Co and $\mathrm{N}$ in the electrocatalysts. The synergetic effect due to catalytically active NCNTs support structures for Pt nanoparticles enhanced the performance of PtCo-NCNTs electrocatalysts. A simple steaming procedure was employed to ensure efficient hydration of Nafion within catalyst-coated membrane and proved to greatly improve fuel cell performance from 392 to $450 \mathrm{~mW} / \mathrm{cm}^{2}$. This work established MOFs as a new platform for the synthesis of novel nano-carbon ORR electrocatalysts for PEMFC as well as a variety of other energy storage and conversion applications.

\section{Acknowledgment}

The authors are thankful to USAID (U.S. Agency for International Development) for financial support. We would also like to thank Dr. A.M. Kannan for his guidance and support. 


\section{References}

[1] F. Barbir, T. Gomez, Efficiency and economics of proton exchange membrane (PEM) fuel cells, Int. J. Hydr. Ener., 22 (1996) 1027-1037.

[2] J.H. Wee, Applications of proton exchange membrane fuel cell systems, Renew. Sustain. Ener. Rrev., 11 (2007) 1720-1738.

[3] K. Sopian, and W.R.W. Daud, Challenges and future developments in proton exchange membrane fuel cells, Ren. Ener., 31 (2006) 719-727.

[4] J.H. Wee, K.Y. Lee, and S.H. Kim, Fabrication methods for Low-Pt-loading electrocatalysts in proton exchange membrane fuel cell systems, J. Pow. Sour., 165 (2007) 667-677.

[5] S. Mukerjee, S. Srinivasan, Enhanced electrocatalysis of oxygen reduction on platinum alloys in proton exchange membrane fuel cells, J. Electroanaly. Chem., 357 (1993) 201-224.

[6] S. Sui, X. Wang, X. Zhou, Y. Su, S. Riffat, C.J. Liu, A comprehensive review of Pt electrocatalysts for the oxygen reduction reaction: Nanostructure, activity, mechanism and carbon support in PEM fuel cells, J. Mat. Chem. A, 5 (2017) 1808-1825.

[7] J. Zhang, PEM fuel cell electrocatalysts and catalyst layers: fundamentals and applications, $1^{\text {st }}$ ed., Springer-Verlag, London, 2008.

[8] P.J. Ferreira, Y. Shao-Horn, D. Morgan, R. Makharia, S. Kocha, H.A. Gasteiger, Instability of $\mathrm{Pt} / \mathrm{C}$ electrocatalysts in proton exchange membrane fuel cells a mechanistic investigation, $\mathrm{J}$. Electrochem., S. 152 (2005) A2256-A2271.

[9] Z.B. Wang, P.J. Zuo, Y.Y. Chu, Y.Y. Shao, G.P. Yin, Durability studies on performance degradation of $\mathrm{Pt} / \mathrm{C}$ catalysts of proton exchange membrane fuel cell, Intl. J. Hydr. Ener., 34 (2013) 4387-4394.

[10] M.S. Wilson, S. Gottesfeld, High Performance Catalyzed Membranes of Ultra-Low Pt Loadings for Polymer Electrolyte Fuel Cells, J. Electrochem. Soc., 139 (1992) L28-30.

[11] P. Mani, R. Srivastava, P. Strasser, Dealloyed Pt- Cu core- shell nanoparticle electrocatalysts for use in PEM fuel cell cathodes, The J. Phy. Chem. C, 112 (2008) 2770-2778.

[12] E.J. Taylor, E.B. Anderson, N.R.K. Vilambi, Preparation of High-Platinum-Utilization Gas Diffusion Electrodes for Proton-Exchange-Membrane Fuel Cells, J. Electroch. Soc., 139 (1992) L45-46.

[13] K. Gong, F. Du, Z. Xia, M. Durstock, L. Dai, Nitrogen-doped carbon nanotube arrays with high electrocatalytic activity for oxygen reduction, Sci., 323 (2009) 760-764.

[14] Z. Chen, D. Higgins, H. Tao, R.S. Hsu, Z. Chen, Highly active nitrogen-doped carbon nanotubes for oxygen reduction reaction in fuel cell applications, J. Phy. Chem. C, 113(2009) 21008-21013.

[15] Y. Shao, J. Sui, G. Yin, Y. Gao, Nitrogen-doped carbon nanostructures and their composites as catalytic materials for proton exchange membrane fuel cell, App. Cat. B: Env., 79 (2008) 89-99.

[16] S. Maldonado, K.J. Stevenson, Influence of nitrogen doping on oxygen reduction electrocatalysis at carbon nanofiber electrodes, J. Phy. Chem. B, 109 (2005) 4707-4716.

[17] D.C. Higgins, D. Meza, Z. Chen, Nitrogen-doped carbon nanotubes as platinum catalyst supports for oxygen reduction reaction in proton exchange membrane fuel cells, The J. Phy. Chem. C, 114 (2010) 21982-21988.

[18] Y. Chen, J. Wang, H. Liu, R. Li, X. Sun, S. Ye, S. Knights, Enhanced stability of Pt electrocatalysts by nitrogen doping in CNTs for PEM fuel cells, Electrochem. Commun., 11 (2009) 2071-2076. 
[19] I.E. Stephens, A.S. Bondarenko, U. Grønbjerg, J. Rossmeisl, I. Chorkendorff, Understanding the electrocatalysis of oxygen reduction on platinum and its alloys, Ener. Environ. Sci., 5 (2012) 6744-6762.

[20] D.A. Muller, D. Wang, F.J. DiSalvo, H.D. Abruña, H. Wang, H.L. Xin, R. Hovden, Y. Yu, Structurally ordered intermetallic platinum-cobalt core-shell nanoparticles with enhanced activity and stability as oxygen reduction electrocatalysts, Nat. Mater., 12 (2013) 81-89.

[21] U.A. Paulus, A. Wokaun, G.G. Scherer, T.J. Schmidt, V. Stamenkovic, V. Radmilovic, N.M. Markovic, P.N. Ross, Oxygen reduction on carbon-supported $\mathrm{Pt}-\mathrm{Ni}$ and $\mathrm{Pt}-\mathrm{Co}$ alloy catalysts, J. Phy. Chem. B, 106 (2002) 4181-4191.

[22] S.T. Meek, J.A. Greathouse, M.D. Allendorf, Metal-organic frameworks: A rapidly growing class of versatile nanoporous materials, Adv. Mater., 23 (2011) 249-267.

[23] E. Proietti, F. Jaouen, M. Lefèvre, N. Larouche, J. Tian, J. Herranz, J.P. Dodelet, Iron-based cathode catalyst with enhanced power density in polymer electrolyte membrane fuel cells, Nat. Comm., 2 (2011) 1427-1432.

[24] H.L. Jiang, B. Liu, Y.Q. Lan, K. Kuratani,T. Akita, H. Shioyama, F. Zong, Q. Xu, From metal-organic framework to nanoporous carbon: toward a very high surface area and hydrogen uptake, J. Amer. Chem. Soc., 133 (2011) 11854-11857.

[25] K.S. Park, Z. Ni, A.P. Côté, J.Y. Choi, R. Huang, F.J. Uribe-Romo, H.K. Chae, M. O'Keeffe, O.M., Yaghi, Exceptional chemical and thermal stability of zeolitic imidazolate frameworks, Proceed. Nat. Acad. Sci., 103 (2006) 10186-10191.

[26] B.Y. Xia, Y. Yan, N. Li, H.B. Wu, X.W.D. Lou, X. Wang, A metal-organic frameworkderived bifunctional oxygen electrocatalyst, Nat. Ener., 1 (2016) 15006-15014.

[27] B. Chen, G. Ma, Y. Zhu, Y. Xia, Metal-organic-frameworks derived cobalt embedded in various carbon structures as bifunctional electrocatalysts for oxygen reduction and evolution reactions, Scient. Rep., 7 (2017) 5266-5271.

[28] S. Zhong, C. Zhan, D. Cao, Zeolitic imidazolate framework-derived nitrogen-doped porous carbons as high performance supercapacitor electrode materials, Carb., 85 (2016) 51-59.

[29] M. Zhiani, S., Majidi, Effect of MEA conditioning on PEMFC performance and EIS response under steady state condition, Intl. J. Hyd. Ener., 38 (2013) 9819-9825.

[30] M. Zhiani, I. Mohammadi, S. Majidi, Membrane electrode assembly steaming as a novel preconditioning procedure in proton exchange membrane fuel cell, Int. J. Hyd. Ener., 42 (2017) 44904500 .

[31] B. Chen, G. Ma, Y. Zhu and Y. Xia, Metal-organic-frameworks derived cobalt embedded in various carbon structures as bifunctional electrocatalysts for oxygen reduction and evolution reactions, Scient. Rep., 7 (2017) 5266.

[32] Y. Chen, J. Wang, H. Liu, M.N. Banis, R. Li, X. Sun, T.K. Sham, S. Ye, S. Knights, Nitrogen doping effects on carbon nanotubes and the origin of the enhanced electrocatalytic activity of supported Pt for proton-exchange membrane fuel cells, J. Phy. Chem., 115 (2011) 3769-3776.

[33] K. Gong, F. Du, Z. Xia, M. Durstock, L. Dai, Nitrogen-doped carbon nanotube arrays with high electrocatalytic activity for oxygen reduction. Sci., 323 (2009) 760-764.

[34] L. Yang, S. Jiang, Y. Zhao, L. Zhu, S. Chen, X. Wang, Q. Wu, J. Ma, Y. Ma, Z. Hu, Borondoped carbon nanotubes as metal-free electrocatalysts for the oxygen reduction reaction, Angewandte. Chemie., 123 (2011) 7270-7273. 
[35] D. Yu, Q. Zhang, L. Dai, Highly efficient metal-free growth of nitrogen-doped single-walled carbon nanotubes on plasma-etched substrates for oxygen reduction, J. Ameri. Chem. Soc., 132 (2010) 15127-15129.

[36] L. Qu, Y. Liu, J.B. Baek, and L. Dai, Nitrogen-doped graphene as efficient metal-free electrocatalyst for oxygen reduction in fuel cells, ACS Nano, 4 (2010) 1321-1326.

[37] L. Xiong, A.M. Kannan, A. Manthiram, Pt-M ( $\mathrm{M}=\mathrm{Fe}, \mathrm{Co}, \mathrm{Ni}$ and $\mathrm{Cu})$ electrocatalysts synthesized by an aqueous route for proton exchange membrane fuel cells, Electro. Commun., 4 (2002) 898-903. 